\title{
THE IMPACT OF KNOWLEDGE MANAGEMENT ON SUSTAINABLE ACTIVITIES OF HIGHER EDUCATION INSTITUTION
}

\author{
Ieva Grybauskiene \\ Faculty of Communication \\ Vilnius University \\ 58 Saltoniškiu str., Vilnius, Lithuania, LT-08105 \\ ievamk13@gmail.com \\ Žymantè Jankauskiené \\ Vilniaus kolegija/University of Applied Sciences \\ 58 Saltoniškiu str., Vilnius, Lithuania, LT-08105 \\ z.jankauskiene@viko.lt \\ Erika Kubiliene \\ Vilniaus kolegija/University of Applied Sciences \\ 58 Saltoniškiu str., Vilnius, Lithuania, LT-08105 \\ e.kubiliene@viko.lt
}

\begin{abstract}
The main responsibilities for the European Higher Education Area are based on processes‘ execution through the knowledge, therefore each institution has to evaluate its own knowledge and organize activities implementing these knowledge goals. Knowledge management $(\mathrm{KM})$ is considered one of the main disciplines of the 21st century, which helps organizations to create a competitive advantage, to identify unique knowledge within the organization and to develop further knowledge creation and integration into activities. KM can be analyzed specifically, however it's recognized that human resources remain the most important factor, which leads to effective implementation of the stages of KM. Preparing trained staff for the knowledge society and economy, who are able to assess the benefits and importance of knowledge, higher education institutions (HEI) shape the future behavior of future market players, define the need for future competences and values. Following this example, it's useful to analyze, how KM processes are integrated into the academic community and which role the KM plays in the development of HEI's activity and competence.

Keywords: knowledge management, expression of knowledge management in higher education, practical application of knowledge management in higher education institution.
\end{abstract}

\section{Introduction}

Knowledge is just an intangible asset that every employee in an organization has. However, such tacit knowledge can become explicit, when the management encourages personal and professional growth of employees knowledge, promoting dissemination of knowledge and skills at all levels of the organization, creating knowledge-susceptible culture and environment. An organization that wants to implement knowledge management (KM) models, needs to identify, which knowledge processes are typical for organization and reflect its work processes in the best way [1].

KM transforms information and intellectual insights into long-term value. It connects people with the appropriate knowledge when it comes to taking appropriate action [2]. KM is an integral and one of the most important parts of the organization. Properly tailored KM can increase organizational efficiency and productivity. Human resources are the key asset of the organization, and in order to improve the performance of the organization, it is necessary to assess the importance and capacity of human resources, as it is the main source of knowledge and knowledge capital for the organization [3].

The extent of knowledge does not ensure a successful KM, because excess knowledge makes it difficult to use, so the quality of knowledge becomes very important. Higher quality of knowledge enables successful implementation of KM practices, as it facilitates the dissemination, 
usage and application of knowledge. Organizations with knowledge of higher quality are considered more innovative and show better financial performance [4].

Higher education institutions (HEIs) share information and knowledge with the community through organizational activities, and this is one of their core responsibilities. It is common for HEIs to be the place for knowledge creation, accumulation, dissemination, therefore, in the context of KM culture, it is important for HEIs to implement KM processes for maintaining core activities [5]. HEIs, seeking to remain competitive, strive to develop and implement such KM methods, that correlate with KM strategies, goals, and also with whole organization strategy [6].

HEIs become the main creator and promoter of knowledge in the knowledge-based society and knowledge-based economy [2, 4, 5, 7]. HEIs perform a role of employer, spreader of technological progress and developer of human resource competences. Assessing knowledge as the significant development factor, KM can encourage HEIs and the whole community to create added value and competitive advantage at the regional, national and international level [8-11]. In recent years the education and science system is experiencing a number of changes. In Lithuania, since November 2018, one of six Lithuania's century reforms has been initiated, reflecting on structural changes in the education system. One of the goals of the reform, oriented towards the higher education chain, is optimization of the network of HEIs in order to increase the prestige of the teacher's profession and quality of study services [12]. HEIs have always been linked to KM. Looking at some of the key goals of higher education - research, education - there are many similarities to the knowledge creation, dissemination and transfer processes [6,13-17]. Taking into account the perspectives of higher education in Lithuania, it's important to identify the main weaknesses and strengths of the system.

Assessing KM as an institution's tool for progress, the research on application of KM processes was performed in Vilniaus kolegija/UAS. Such kind of studies have not been conducted in Lithuania yet.

Such type of research has been conducted in Pakistan [18], in Malaysia [19, 20] in Thailand [21], and in United States [22]. The research have shown, that employees in the implementation of $\mathrm{KM}$ are most likely to appreciate the prevailing favorable organizational culture.

It's recognized that it helps to transform unspoken knowledge into expressed knowledge, KM encourages employees to be interested in innovations and apply it in practice [1, 3, 23-25].

The aim of the article - to investigate assumptions for knowledge management expression in higher education institution - Vilniaus kolegija/UAS.

\section{Materials and Methodology}

The research consisted of three stages. The first stage - analysis of Institution's Strategic Plan, aimed at reviewing the elements of Institution's strategic plan and determining, if the organization supports a conducive environment for KM dissemination.

The second stage - presentation of KM model, analysis of KM and its tools, based on selected model, aimed at carrying out a questionnaire survey for teachers to find out their views and assessments, functioning of KM processes, management and interfaces, the relation with respondents' socio-demographic indicators.

The third stage - evaluation and statistical analysis of research results using IBM SPSS Statistics 23 software, aimed at identifying statistically significant relationships among implementation of individual KM processes in the Institution.

According to G. Probst's Knowledge Management Model, a questionnaire for survey was created. The main part of the survey contains 43 statements, which were divided into 8 blocks according to the research model. Each block contains from 4 to 6 statements, which need to be supported choosing, according to the Likert scale, the most appropriate option: " agree", "partly agree", "partly disagree", "disagree", "do not know". While interpreting the options, it was considered the options «agree» and «partly agree» to treat as positive evaluation, the options «partly disagree», «disagree» and «do not know» - as choices for unfavorable assessment. The questionnaire contains two demographic questions. 
The questionnaire, developed in October 2018, was available only to the staff of HEI Vilniaus kolegija/UAS. According to the data of the Institution, there were 317 teachers in October 2018, to whom this HEI is the main workplace. The representative sample size, calculated according to Paniott formula, is 176 . In our case 183 respondents participated in the survey, so it can be concluded, that the results of the study are representative.

For the empirical research, a quantitative research method was chosen, which was implemented using the questionnaire survey model. The questionnaire allowed to evaluate effectively KM processes and their functioning in the Institution. IBM SPSS Statistics 23 software was used to process empirical data. A statistical method of data analysis was used to analyze the frequency and correlation of data attributes. Assessing the suitability of the chosen theoretical model, a factor analysis was carried out to identify the most important aspects of the study.

\section{Results and Discussion}

Many aspects, which require changes and integrated solutions, prevail in the elements of Vilniaus kolegija/UAS Strategic Plan until 2020 (Fig. 1). From the perspective of KM, knowledge organization, which evaluates and acquires the missing knowledge in order to pursue the necessary competences to maintain competitive advantage, is being developed. While analyzing the Institution's vision and mission, it could be observed, that most of the statements reflect the general organization's competences, and this means, that the vision and mission seek to bring about the realization of employees ${ }^{\star}$ knowledge and competences in the performance of the Institution's activities. Therefore, investing into employees` knowledge becomes a key prerequisite for the Strategic Plan of Vilniaus kolegija/UAS.

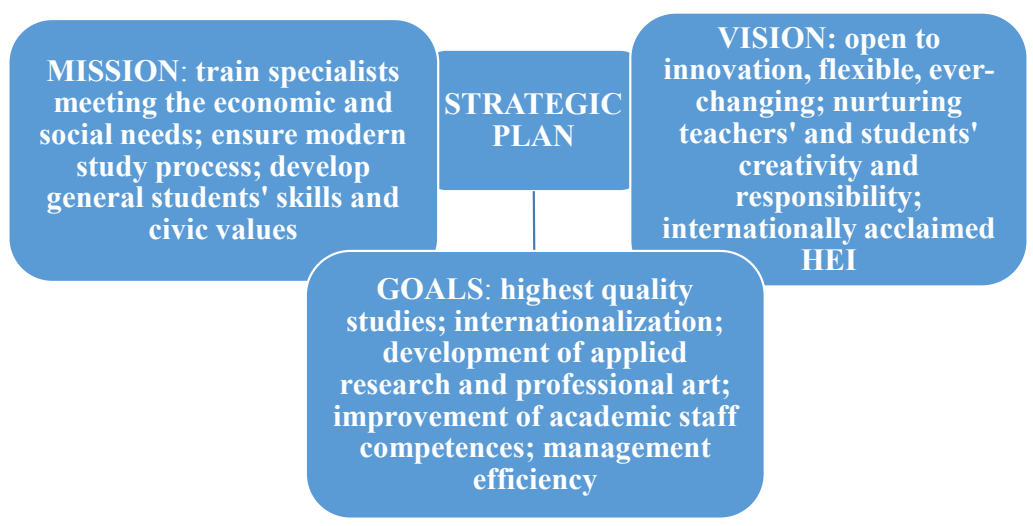

Fig. 1. Elements of the Strategic Plan of Vilniaus kolegija/UAS (composed by authors)

Although only one goal of the Strategic Plan (to improve the competences of the academic staff) is directly reflected to the goals of the community, it's worth to recognize, that the remaining goals, although not directly mentioned, are directed to the activities of academic and non-academic staff, their improvement and development. To achieve the goal of the research, the Gilbert Probst (1998) model "Building Blocks of Knowledge Management" was selected, which represents processes, the sequence of processes in the model with the corresponding meaning and directly knowledge-orienting (Fig. 2).

The internal cycle of the Model consists of identification, acquisition, development, dissemination, retention and usage stages of knowledge.

The external cycle of the Model consists of the same stages mentioned above and stages for setting and evaluating of knowledge goals, that generate links among each other to assess the success of the whole cycle, whereas only after assessment of knowledge it can be concluded whether the goal has been achieved [26].

The stages of KM should not be isolated from one another, whereas missed one step increases the likelihood that the cycle will not succeed. The KM model will also not be successful, if the development of internal organization knowledge does not correlate with the organization's goals 
and future needs. The model can help employees systematize their knowledge, deepen it, and at the same time gain the missing knowledge.

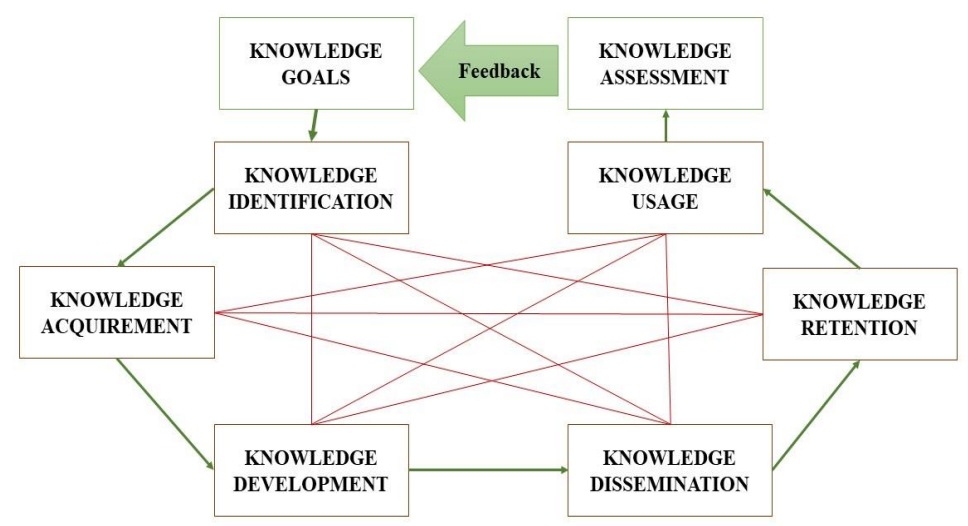

Fig. 2. G. Probst knowledge management model

"Building Blocks of Knowledge Management" [26]

Teachers were chosen as respondents' group, because $45 \%$ of all staff in the Institution are teachers, and, according to the nature of the work of this staff group, exactly analysis of this segment reveals the challenges raised for the research.

In order to find out whether the age of teachers and the length of their pedagogical work are important for the answers, chosen by the respondents, two demographic questions were presented in the questionnaire. Representatives of age groups from 35 till 64 were most active in the study (3544 year age group $31 \%$, 4554 year age group $27 \%$, 5564 year age group $24 \%$ ).

According to the survey, more than one third of respondents (39\%) are teachers with more than 20 years of pedagogical work. Another third of respondents are teachers with from 10 to 19 year pedagogical workload (36\%), one fourth of respondents was those with up to 9 years of pedagogical work experience (25\%).

First of all, based on the results of the survey, the blocks of statements were reviewed and assessed. The investigative factor analysis of each block of statements was performed to identify inter-correlation links of statements. Assessing the Kaiser-Meyer-Olkin (KMO) coefficient (KMO>0,5), Bartlett's Test of Sphericity" (significance level ("Sig.”) < 0,05), the relevance of the statements for factor analysis was determined. After evaluation of each block statements' dispersion, the key factors were determined - the statements explaining the largest part of all statements' spread.

The first block of statements (1), called "Knowledge Goals", aimed at determining whether the employee knows and understands the Institution's strategy, objectives, approach: Institution's strategy for the teacher is clear and understandable (A); Teacher supports the changes in the institution (B); Teacher knows the requirements and expectations related to activities (C); Institution has clearly defined objectives for continuous improvement of teachers' competences (D); It's important for the institution that each teacher develops in professional field (E); Teacher's professional development influences institution's performance $(\mathrm{F})$.

Results of the analysis have shown, that the majority of respondents (over $78 \%$ ) agree or at least partly agree with Institution's knowledge goals. This leads to the conclusion, that employees are familiar with the organisation's strategic activities (A) and know, which knowledge and competences are needed for participating in the Institution's activities successfully (C). It is worth to emphasize, that the majority of respondents $(81 \%)$ agree, that institution's results are conditioned by the professional development of teachers $(\mathrm{F})$, thus, it can be assumed, that teachers fully understand the influence of their professional role implementing strategic goals of the Institution.

After the correlation analysis between the statements in the block «Knowledge Goals» and the distribution of respondents according to pedagogical work experience, statistically significant 
relationships were determined in the segment of respondents with a pedagogical work experience up to 5 years. With increasing age of respondents, the tendency, that respondents are more aware of the Institution's strategy and competence development goals was observed. Among younger respondents, changes in the institution, acceptance of requirements and expectations, professional development of teachers were supported stronger.

These results could be interpreted in different ways: it can be assumed, that younger people with a low pedagogical experience have not yet become familiar with the Institution's strategic plan and ongoing competence development programs. It could be also assumed, that the previous work experience of older respondents influences the perception of change and professional development importance and leads to the more favorable assessment of these aspects.

Weak and moderate statistically significant $(\mathrm{p}<0,05)$ and acceptable for factor analysis $(\mathrm{KMO}>0,5)$ inter-correlations between the block «Knowledge Goals» statements were determined (Table 1).

Table 1

Inter-correlation analysis (Spearman correlation coefficient $\mathrm{R}$ ) of statements` block (1) «Knowledge Goals» $(\mathrm{N}=183)$

\begin{tabular}{|c|c|c|c|c|c|c|}
\hline & $\mathbf{A}$ & B & C & D & $\mathbf{E}$ & $\mathbf{F}$ \\
\hline A & & $0,638^{*}$ & $0,562 *$ & $0,557^{*}$ & $0,435^{*}$ & $0,306^{*}$ \\
\hline B & & & $0,422^{*}$ & $0,433^{*}$ & $0,359^{*}$ & $0,357^{*}$ \\
\hline $\mathrm{C}$ & & & & $0,638^{*}$ & $0,468^{*}$ & $0,360 *$ \\
\hline $\mathrm{D}$ & & & & & $0,586^{*}$ & $0,337^{*}$ \\
\hline $\mathrm{E}$ & & & & & & $0,300^{*}$ \\
\hline $\mathrm{F}$ & & & & & & \\
\hline
\end{tabular}

Statistically significant direct correlations of medium strength $(R=0,638)$ were found between the statement A and statement B, between the statement $\mathrm{C}$ and statement $\mathrm{D}$.

During factorization of the statements' block (1) «Knowledge Goals» the SPSS programme extracted 1 factor, which explains $54,82 \%$ of all variables' spread $(\mathrm{N}=183$, Cronbach $\alpha=0,832$; $K M O=0,823$, Bartlett's Test of Sphericity $=398,3, \mathrm{p}=0,000$, Varimax rotation).

The second block of statements (2), called "Knowledge Identification" aimed at interpretation and understanding of knowledge: Teacher discusses professional development plans with the direct manager (A); Teacher discusses formulated challenges and assigned tasks with the direct manager (B); Teacher analyzes problems, encountered in the work activity (C); Improvement of teacher's professional competences contributes to the achievement of Institution's strategic goals (D).

Obtained research results have shown, that the majority of respondents (over $80 \%$ ) discuss about professional plans and tasks together with managers (statements A and B). Existing employee's knowledge, competences and possibilities for acquiring knowledge are identified in cooperation with the manager. At the same time, a teacher analyzes the work activity individually (C), contributing to the improvement of the institution's activities (D).

Following the correlation analysis between block's "Knowledge Identification" statements and the distribution of respondents according to the pedagogical work experience, statistically significant relationships were determined between respondents' with up to 5 years pedagogical work experience with approach to the statement Institution creates conditions for improving teacher's competence - very weak reverse dependence $(\mathrm{R}=0,062)$. In the respondents' segment with the pedagogical work experience from 10 to 14 years - statistically significant relationship was determined with approach to the statement Improvement of teacher's professional competences contributes to the Institution's strategic goals (D) - weak direct dependence $(\mathrm{R}=0,085)$. For the pedagogical work experience up to 5 years there is a tendency, that the assertion with the statement about the improvement of the teacher's competences increases with the increase of the respondent's age. This choice can also be explained by more active involvement of older workers in competence 
development processes, because the short pedagogical experience does not give enough time and opportunities. Respondents with the greater pedagogical work experience (from 10 to 14 years) support the statement that Improving teacher's competences is a tool for the institution's strategic goals (D) and this approval gets stronger when respondents' age is decreasing.

Statistically significant $(\mathrm{p}<0.05)$ and acceptable for factor analysis $(\mathrm{KMO}>0.5)$ inter-correlations were determined between "Knowledge Identification"statements (Table 2).

Table 2

Inter-correlation analysis (Spearman correlation coefficient $R$ ) of statements` block (2) «Knowledge Identification" $(\mathrm{N}=183)$

\begin{tabular}{ccccc}
\hline & A & B & C & D \\
\hline A & & $\mathbf{0 , 7 7 7 ^ { * }}$ & $0,503^{*}$ & $0,340^{*}$ \\
B & & $0,538^{*}$ & $0,228^{*}$ \\
C & & & $0,450^{*}$ \\
D & & &
\end{tabular}

Note: $*$ - statistically significant, $p<0.05$

The statistically reliable direct strong correlation $(\mathrm{R}=0.777)$ has been determined between the statement $\mathrm{A}$ and statement $\mathrm{B}$.

During factorization of the statements" block (2) "Knowledge Identification", SPSS programme extracted 1 factor, which explains $61,31 \%$ of all variables' dissemination ( $\mathrm{N}=183$, Cronbach $\alpha=0,786$; $K M O=0,650$, Bartlett's Test of Sphericity=282,7, $p=0,000$, Varimax rotation).

The third block of statements (3) contains claims aimed to identify the processes of "Knowledge Acquirement": System for teachers ' competence development is developed in the Institution (A); Institution provides conditions for improvement of teacher's competences (B); Teacher's internal motivation for lifelong learning is promoted by the Institution $(\mathrm{C})$; Teacher is required to develop competences necessary to ensure the quality of studies (D); Competence development events, organized by the Institution, are relevant (E); Institution provides opportunities to participate in external competence development events (F).

The analysis of the research results has shown, that there is a tendency, that the majority of respondents (over $80 \%$ ) agree or partially agree with the statements that processes, which lead to the knowledge acquisition, are taking place in the institution (B) and these processess provide opportunities to acquire relevant and useful knowledge (E). However, in this case, a large number of respondents tend to only partially agree with these statements, so, it could be assumed, that although these statements are assessed positively, for most respondents the process is not entirely clear. This is illustrated by the moderate acceptance of statements and fact, that close to half of respondents (40\%) oppose (disagree or do not know) to the statement Institution has developed a system for improving teachers' competences (A).

After carrying out the correlation analysis between the statements «Knowledge Acquirement» and the distribution of respondents according to the pedagogical work experience, a statistically significant weak link $(\mathrm{R}=0,281)$ between respondents with the pedagogical work experience from 20 years and more and the statement B was determined. It can be assumed, that older teachers are relatively more involved in competence improvement activities, organized by the Institution, and, simultaneously, the activities provided by the Institution for younger teachers are insufficient.

Statistically significant $(\mathrm{p}<0,05)$ and acceptable for factor analysis $(\mathrm{KMO}>0,5)$ weak and moderate inter-correlations were determined between "Knowledge Acquirement" statements (Table 3).

The statistically reliable direct correlation of medium strength $(\mathrm{R}=0.670)$ was determined between the statement B and statement F.

During factorization of the statements" block (3) "Knowledge Acquirement" SPSS programme extracted 1 factor, explaining $61,10 \%$ of all variables' dissemination $(\mathrm{N}=183$, Cronbach $\alpha=0,870 ; K M O=0,866$, Bartlett's Test of Sphericity $=511,8, \mathrm{p}=0,000$, Varimax rotation). 
Table 3

Inter-correlation analysis (Spearman correlation coefficient $R$ ) of statements" block (3) "Knowledge Acquirement" $(\mathrm{N}=183)$

\begin{tabular}{|c|c|c|c|c|c|c|}
\hline & A & B & C & D & $\mathbf{E}$ & $\mathbf{F}$ \\
\hline A & & $0,639 *$ & $0,669^{*}$ & $0,509 *$ & $0,574^{*}$ & $0,449 *$ \\
\hline B & & & $0,646^{*}$ & $0,524 *$ & $0,533^{*}$ & $0,670 *$ \\
\hline $\mathrm{C}$ & & & & $0,492 *$ & $0,605^{*}$ & $0,467^{*}$ \\
\hline D & & & & & $0,393^{*}$ & $0,391^{*}$ \\
\hline $\mathrm{E}$ & & & & & & $0,366^{*}$ \\
\hline F & & & & & & \\
\hline
\end{tabular}

Note: ${ }^{*}$ - statistically significant, $p<0.05$

The fourth block of statements (4) "Knowledge Development" aimed to determine, whether the teacher engages in knowledge development processes, whether the Institution supports and promotes these processes, who does initiate the development of knowledge in the Institution: Teachers are actively involved in developing competences (A); Faculty/Department provides information on possible competences' development events (B); Faculty/Department initiates and mediates organizing competence development events within the institution (C); Teachers are looking for information on competence development themselves (D); Teacher maintains constant contacts with the work world and participates in organized events, internships etc. (E); Teachers' good practice dissemination events, where new knowledge could be gained, take place in Faculty/Department (F).

The analysis of the research results showed, that the vast majority of respondents support or partially support the development of knowledge (over $77 \%$ ). When evaluating faculty's/department's initiatives in knowledge development activities (statements B and C), most of them (over $90 \%$ ) support and partially support the involvement of the Institution. However, when evaluating the involvement of an employee and active participation of a teacher in knowledge development activities (A), not a small number of respondents (44\%) only partially agrees with this idea and $7 \%$ of respondents even do not know whether they are improving their competences actively or not. Close to a half of respondents ( $46 \%$ ) agree, that they are looking for information about competence development events independently (D).

Following the correlation analysis between the "Knowledge Development" block statements and the distribution of respondents according to their pedagogical work experience, statistically significant relationships between respondents with the pedagogical work experience from 10 to 14 years and statement Faculty/Department provides information on possible competence development events (B) (weak reverse dependence $\mathrm{R}=0,285$ ) and between respondents with the pedagogical work experience up to 5 years and statements Teachers are looking for information about competence development events themselves (D) (reverse very weak dependence $\mathrm{R}=0,051$ ); Teacher maintains a constant contacts with the work world and participates in organized events, internships etc. (E) (very weak direct dependence $\mathrm{R}=0,127$ ) were identified. For the pedagogical work experience from 10 to 14 years it was noted, that the approval of the statement that Faculty/Department provides information on possible competence development events (B) is strengthened by a direct proportional increase in the age of respondents. It can be assumed, that older teachers are more involved in the activities of the faculty and the proposed events; the information provided by the institution may not be sufficient to meet the needs of younger professionals.

Weak and moderate statistically significant $(\mathrm{p}<0,05)$ and acceptable for factor analysis $(\mathrm{KMO}>0,5)$ inter-correlations between statements of "Knowledge Development"(4) block were determined (Table 4).

The statistically reliable direct correlation of medium strength $(\mathrm{R}=0.664)$ was determined between the statement $\mathrm{B}$ and statement $\mathrm{C}$.

During factorization of the statements“ block (4) „Knowledge Development" ( $\mathrm{N}=183$, Cronbach $\alpha=0,720 ; \mathrm{KMO}=0,700$, Bartlett's Test of Sphericity $=302,5, \mathrm{p}=0,000$, Varimax rotation), SPSS programme extracted 2 factors which explain $66,64 \%$ of all variables' dissemination. The first 
factor (F1) combines statements that characterize institution-driven knowledge development processes, the second factor (F2) combines statements that indicate the individual awareness-raising initiative outside the institution.

\section{Table 4}

Inter-correlation analysis (Spearman correlation coefficient R) of statements“ block (4) „Knowledge Development" ( $\mathrm{N}=183)$

\begin{tabular}{|c|c|c|c|c|c|c|}
\hline & $\mathbf{A}$ & B & C & D & $\mathbf{E}$ & $\mathbf{F}$ \\
\hline A & & $0,355^{*}$ & $0,461^{*}$ & $0,048^{*}$ & $0,414^{*}$ & $0,376^{*}$ \\
\hline B & & & $0,664^{*}$ & $0,007 *$ & $0,328^{*}$ & $0,495^{*}$ \\
\hline $\mathrm{C}$ & & & & $0,069 *$ & $0,251^{*}$ & $0,473 *$ \\
\hline D & & & & & $0,425^{*}$ & 0,006 \\
\hline $\mathrm{E}$ & & & & & & $0,258^{*}$ \\
\hline F & & & & & & \\
\hline
\end{tabular}

The fifth block of statements, called "Knowledge Dissemination" (5), aimed at competence development events, sharing good practice, personal achievements, the prevailing atmosphere: Teacher is encouraged to participate in the institution/academic unit staff competence development events (A); Institution has a favorable atmosphere, encouraging teachers to share good practice (B); Organization of good practice dissemination events is promoted through various encouragement forms (C); Teacher's suggestions and ideas are heard and discussed with direct managers (D); Teacher's professional achievements are announced (E); Teacher's professional achievements have a positive impact on the Institution's visibility and prestige (F).

The analysis of the survey results has shown, that the majority of respondents (over $60 \%$ ) agree and support the processes of knowledge dissemination, but in this block of statements there is an increased proportion of respondents who disagree.

One third of respondents (31\%) fully or partially disagree with the statement that the organization of good practice events is encouraged (C), and one tenth of respondents do not know how properly to assess this statement. One fifth of respondents disagree or partly disagree with the statement that the Teacher's suggestions and ideas are heard (D). While there is the general agreement on the statements, it is necessary to take into account and evaluate the opinion of the disagreed respondents, as the vast majority of respondents agree $(71 \%)$ or partly agree $(21 \%)$ with the statement that Teacher's professional achievements influence the reputation and prestige of the institution (F). Therefore, it can be assumed that the knowledge dissemination and the results of this process are important for teachers.

After the analysis correlation analysis between knowledge dissemination block statements and distribution of respondents according to the pedagogical work experience, no statistically significant relations were determined.

Weak and moderate statistically significant $(\mathrm{p}<0.05)$ and acceptable for factor analysis $(\mathrm{KMO}>0.5)$ inter-correlations were determined for statements" block (5) "Knowledge Dissemination“" (Table 5).

The statistically reliable direct correlation of medium strength $(\mathrm{R}=0.577)$ relates the statement $\mathrm{B}$ and statement $\mathrm{C}$.

During factorization of the statements' block (5) „Knowledge Dissemination“ ( $\mathrm{N}=183$, Cronbach $\alpha=0,823 ; \mathrm{KMO}=0,833$, Bartlett's Test of Sphericity $=348,5, \mathrm{p}=0,000$, Varimax rotation) SPSS programme extracted 1 factor, which explains $53,51 \%$ of all variables' spread.

The sixth block of statements (6) contains propositions on "Knowledge Retention": Examples of teachers' good practice are collected in virtual repositories (A); Teachers can use the methodological publications, conference materials, video lectures, etc., collected in virtual repositories (B); Academic information system helps the teacher to administer the taught subject/ module (C); Teachers apply the newly acquired knowledge creatively (D). 
Table 5

Inter-correlation analysis (Spearman correlation coefficient R) of statements" block (5) "Knowledge Dissemination “ ( $\mathrm{N}=183)$

\begin{tabular}{|c|c|c|c|c|c|c|}
\hline & $\mathbf{A}$ & B & C & D & $\mathbf{E}$ & $\mathbf{F}$ \\
\hline A & & $0,535^{*}$ & $0,509^{*}$ & $0,501^{*}$ & $0,481^{*}$ & $0,301 *$ \\
\hline B & & & $0,577^{*}$ & $0,438^{*}$ & $0,417^{*}$ & $0,401 *$ \\
\hline $\mathrm{C}$ & & & & $0,376^{*}$ & $0,411^{*}$ & $0,369^{*}$ \\
\hline D & & & & & $0,426^{*}$ & $0,348^{*}$ \\
\hline $\mathrm{E}$ & & & & & & $0,516^{*}$ \\
\hline $\mathrm{F}$ & & & & & & \\
\hline
\end{tabular}

Note: ${ }^{*}$ - statistically significant, $p<0.05$

It was determined, that almost one third of respondents (30\%) do not know, whether teachers' good practice examples are being retained (A), and more than one fifth of respondents (21\%) are unaware of the availability of information, collected in virtual repositories and the knowledge, provided by the repository (B). It can be assumed, that the Institution does not have a well-defined knowledge retention system, employees cannot accurately define and evaluate their knowledge retention capabilities, although they agree or partly agree that the Information system helps to manage study activities and Creatively adapt gained knowledge in practice (statements C and D $80 \%$ and $86 \%$ respectively).

Following the correlation analysis between "Knowledge Retention" statements and pedagogical work experience, a statistically significant, very weak reverse dependence was determined $(\mathrm{R}=-0.184)$ between teachers with the pedagogical work experience of 10 to 14-year and the statement Teachers can use the methodological publications, conference materials, video lectures, etc., collected in virtual repositories etc. (B). Older teachers are more tended to accept this statement, and it could be assumed, that they are more likely to use information in virtual repositories, although, as mentioned earlier, the majority of respondents are not aware of virtual repositories. This leads to statistically insignificant choices among teachers with another pedagogical experience.

Statistically significant $(\mathrm{p}<0,05)$ and acceptable for factor analysis $(\mathrm{KMO}>0,5)$, weak and moderate inter-correlations of statements" block (6) "Knowledge Retention" were determined (Table 6).

\section{Table 6}

Inter-correlation analysis (Spearman correlation coefficient R) of statements' block (6) "Knowledge Retention" $(\mathrm{N}=183)$

\begin{tabular}{ccccc}
\hline & A & B & C & D \\
\hline A & & $\mathbf{0 , 6 7 9 *}$ & $0,366^{*}$ & $0,406^{*}$ \\
B & & & $0,362^{*}$ & $0,296^{*}$ \\
C & & & $0,253^{*}$ \\
D & & &
\end{tabular}

Note: * - statistically significant, $p<0,05$

The statistically reliable direct correlation of medium strength $(\mathrm{R}=0.679)$ was determined between the statement A and statement B.

During factorization of the statements“ block (6) ,Knowledge Retention“ ( $\mathrm{N}=183$, Cronbach $\alpha=0,731$; $K M O=0,677$, Bartlett's Test of Sphericity=177,3, $p=0,000$, Varimax rotation) SPSS programme extracted 1 factor, which explains $55,33 \%$ of all variables' spread.

The seventh block of statements (7), called "Knowledge Usage", contains claims, aimed at evaluating how teacher's obtained knowledge is used in practice: Teachers gain useful information and knowledge during their competence development (A); Teacher applies new obtained knowledge in the professional activity (B); Newly acquired knowledge helps to solve problems (C); Newly 
acquired knowledge encourages teacher to continue to be interested in innovation (D); Teacher lacks time to apply newly acquired knowledge and innovations in the professional activity (E).

According to the obtained results, there is a tendency that more than a half of respondents (67\% and $73 \%$ respectively) agree with the statements that Acquired information and knowledge are useful (A) and adaptable in the professional activity (B), new knowledge encourages a teacher to broaden a knowledge scope (D) and solve the problems, arising in the professional activity (C). However, only one third of respondents (34\%) agree, that they have enough time to apply innovations in their professional life, more than a half of teachers $(61 \%)$ agree or partly agree, that there is a constant lack of time to apply innovations in practice (E). The distribution of respondents' responses can be assessed quite individually, as there is a difference in the workload of teachers, study and evaluation methods applied, higher education didactics.

The statistical analysis has revealed statistically significant relationships between respondents with the pedagogical work experience from 10 to 14 year and "Knowledge Usage" block statements Teachers gain useful information and knowledge during training (A) - a weak reverse dependence $(\mathrm{R}=-0,441)$, and the Teachers apply newly acquired knowledge in the professional activity (B) - a weak reverse dependence $(\mathrm{R}=0,411)$. The statistically significant relation has been established between teachers with the pedagogical experience of up to 5 years and statements newly acquired knowledge encourages the teacher to continue to be interested in innovations (D) - a very weak direct dependence $(\mathrm{R}=0,134)$, teacher lacks time to apply innovations in the professional activity $(\mathrm{E})$ - a very weak reverse dependence $(\mathrm{R}=-0,076)$. The statistically significant relation and weak reverse dependence $(\mathrm{R}=-0,19)$ was determined between the statement newly acquired knowledge encourages the teacher to continue to be interested in innovation (D) and respondents with 20 and more years of pedagogical experience. For the pedagogical work experience from 10 to 14 years and from 20 and over, there is a tendency for older teachers to support both statements Teachers gain useful information and knowledge during their competence development (A) and Teachers apply newly obtained knowledge in the professional activity (B), so these two statements are relatively correlated, since evaluation whether the knowledge is useful depends on whether knowledge is used successfully in professional activities. Newly acquired knowledge encourages younger teachers to be interested in innovations, but at the same time younger teachers are less supportive to the statement, that there is a lack of time to put the innovations into practice. Although the majority of older teachers agree with statement teacher lacks time to apply innovations in the professional activity (E), and this trend is only observed in respondents with a low pedagogical experience. Respondents, whose pedagogical work experience is 20 or more years, are also interested in innovations regardless of age.

It can be assumed, that it's easier to interpret and realise innovations for younger teachers, as they are more responsive to the dynamic environment and innovations of the modern world, on the other hand, with the increasing pedagogical experience, the attitude towards innovation is changing, and teachers tend to appreciate it more favorably.

Statistically significant $(\mathrm{p}<0,05)$ and acceptable for factor analysis $(\mathrm{KMO}>0,5)$ moderate inter-correlations of statements" block (7) "Knowledge Usage" were determined (Table 7).

Statistically reliable direct correlations of medium strength $(\mathrm{R}=0.689 ; \mathrm{R}=0.697)$ were determined between statements $\mathrm{C}$ and $\mathrm{D}$, and between the statements $\mathrm{B}$ and $\mathrm{C}$ respectively.

During factorization of the statements" block (7) "Knowledge Usage" ( $\mathrm{N}=183$, Cronbach $\alpha=0,726 ; K M O=0,748$, Bartlett's Test of Sphericity=376,6, $p=0,000$, Varimax rotation), the SPSS programme extracted 1 factor explaining $57,86 \%$ of all variables' spread.

The eighth statement block (8) aimed at assessment of knowledge: Teacher analyzes the results of the professional activity with direct manager (A); Teacher devotes time for self-analysis of the professional activity (B); Analysis of the professional activity promotes the professional development of a teacher (C); Assessment of the teacher's professional activity by students and direct supervisor encourages the teacher to improve (D); Analysis of teacher's activities is only a formal procedure (E); Institution promotes the teacher's continuous competence development $(\mathrm{F})$. 
Table 7

Inter-correlation analysis (Spearman correlation coefficient $\mathrm{R}$ ) of statements" block (7) "Knowledge Usage" $(\mathrm{N}=183)$

\begin{tabular}{cccccc}
\hline & A & B & C & D & E \\
\hline A & $0,667^{*}$ & $0,557^{*}$ & $0,613^{*}$ & $0,093^{*}$ \\
B & & $\mathbf{0 , 6 9 7 *}^{*}$ & $0,553^{*}$ & $0,051^{*}$ \\
C & & & $0,689^{*}$ & $0,006^{*}$ \\
D & & & & $0,034^{*}$ \\
E & & & &
\end{tabular}

Note: ${ }^{*}$ - statistically significant, $p<0,05$

The vast majority of respondents (over $79 \%$ ) analyze the results of activities with a direct manager (A), as well as perform self-evaluation independently (B), and support or at least partially support the statement, that analysis of the activity (both individual and feedback from students/ managers) is one of the ways for the professional development ( $\mathrm{C}$ and $\mathrm{D})$. Almost one third of respondents (31\%) disagree or partly disagree with the statement that Analysis of teacher's activities is only a formal procedure (E), but still, just more than a half of respondents (63\%), support or partially support this statement, which suggests that performance analysis is not individualized and teachers lack personalized assessment and analysis.

No statistically significant correlations were found between the "Knowledge Assessment" statements and the length of the teachers' pedagogical work experience.

Statistically significant $(\mathrm{p}<0,05)$ and acceptable for factor analysis $(\mathrm{KMO}>0,5)$ weak and moderate inter-correlations of statements" block (8) "Knowledge Assessment" were determined (Table 8).

\section{Table 8}

Inter-correlation analysis (Spearman correlation coefficient R) of statements" block (8) "Knowledge Assessment" ( $\mathrm{N}=183)$

\begin{tabular}{|c|c|c|c|c|c|c|}
\hline & $\mathbf{A}$ & B & C & D & $\mathbf{E}$ & $\mathbf{F}$ \\
\hline A & & $0,495^{*}$ & $0,495^{*}$ & $0,633 *$ & $0,068^{*}$ & $0,340^{*}$ \\
\hline B & & & $0,556^{*}$ & $0,452^{*}$ & $0,034^{*}$ & $0,343 *$ \\
\hline $\mathrm{C}$ & & & & $0,571^{*}$ & $0,082^{*}$ & $0,457^{*}$ \\
\hline D & & & & & $0,012^{*}$ & $0,351^{*}$ \\
\hline $\mathrm{E}$ & & & & & & 0,024 \\
\hline F & & & & & & \\
\hline
\end{tabular}

The statistically reliable direct correlation of medium strength $(\mathrm{R}=0.633)$ was determined between the statements A and D.

During factorization of the statements" block (8) "Knowledge Assessment" (N=183,Cronbach $\alpha=0,703 ; K M O=0,796$, Bartlett's Test of Sphericity $=305,7, p=0,000$, Varimax rotation) SPSS program extracted 1 factor explaining $48,35 \%$ of all variables' spread.

\section{Conclusions}

1. Higher education institution, providing studies of highest quality standards and taking into account the continuous progress in the sector, is forced to integrate into national and international environment, therefore, the impact of knowledge management and its tools is identified in various forms, through optimization of academic and administrative processes, development of teachers' competences, creation of relationships with students, employers, teachers and formation of a holistic approach to knowledge. 
2. Analyzing knowledge management processes, according to the questionnaire developed by G. Probst's Knowledge Management Model, it was found, that the vast majority of respondents tend to support the statements reflecting on the knowledge management processes, supported by the knowledge management activity in the institution. However, there is a problematic assessment of knowledge development, retention, usage and evaluation statements, which reveals an unfavorable attitude of respondents to the possibilities of using virtual repositories in the Institution, the system of competence development, application of innovations in professional activities and personalized assessment of teachers' activity. Highlighted deficiencies in knowledge management may limit implementation of knowledge management processes within the Institution.

3. According to the correlation analysis among statements in separate knowledge management blocks, it has been found, that young teachers with a low pedagogical experience are more often disadvantaged in the situation, therefore it can be assumed that teachers of this segment are still not sufficiently integrated into the academic community.

4. In accordance with the internal consistency analysis of knowledge management model's statements (Cronbach $\alpha$ ranges from 0,703 to 0,870 ), the homogeneity of the selected statements in the individual kowledge management blocks and their suitability for the factor analysis have been confirmed. After performing the factor analysis of statements in each knowledge management block, 9 diagnostic criteria, reflecting statistically significant and reliable statements, based on the chosen knowledge management model, have been developed. So, the knowledge management expression in Vilniaus kolegija/UAS has been approved, and this presupposes the improvement of whole organization's competences and sustainable activities in the future.

\section{References}

[1] Fowlin, J. M., Cennamo, K. S. (2016). Approaching Knowledge Management Through the Lens of the Knowledge Life Cycle: a Case Study Investigation. TechTrends, 61 (1), 55-64. doi: http://doi.org/ 10.1007/s11528-016-0126-4

[2] López, S. G., Benítez, J. L. S., Sánchez, J. M. A. (2015). Social Knowledge Management from the Social Responsibility of the University for the Promotion of Sustainable Development. Procedia - Social and Behavioral Sciences, 191, 2112-2116. doi: http://doi.org/10.1016/j.sbspro.2015.04.327

[3] Akbari, N., Ghaffari, A. (2017). Verifying Relationship of Knowledge Management Initiatives and the Empowerment of Human Resources. Journal of Knowledge Management, 21 (5), 1120-1141. doi: http://doi.org/10.1108/jkm-10-2016-0435

[4] Bharati, P., Zhang, W., Chaudhury, A. (2015). Better knowledge with social media? Exploring the roles of social capital and organizational knowledge management. Journal of Knowledge Management, 19 (3), 456-475. doi: http://doi.org/10.1108/jkm-11-2014-0467

[5] Charles, W., Nawe, J. (2017). Knowledge Management Practices in Institutions of Higher Learning in Tanzania with Reference to Mbeya University of Science and Technology. University of Dares Salaam Library Journal, 12, 48-65.

[6] Veer Ramjeawon, P., Rowley, J. (2017). Knowledge management in higher education institutions: enablers and barriers in Mauritius. The Learning Organization, 24 (5), 366-377. doi: http://doi.org/10.1108/ tlo-03-2017-0030

[7] Campanella, F., Della Peruta, M. R., Del Giudice, M. (2013). The Role of Sociocultural Background on the Characteristics and the Financing of Youth Entrepreneurship. An Exploratory Study of University Graduates in Italy. Journal of the Knowledge Economy, 4 (3), 244-259. doi: http://doi.org/10.1007/ s13132-013-0157-4

[8] Nawaz, N., Gomes, A. (2014). Review of Knowledge Management in Higher Education Institutions. European Journal of Business and Management, 6 (7), 71-79. Available at: https://www.researchgate.net/ publication/271132392_Review_of_Knowledge_Management_in_Higher_Education_Institutions

[9] Devi Ramachandran, S., Chong, S., Wong, K. (2013). Knowledge management practices and enablers in public universities: a gap analysis. Campus-Wide Information Systems, 30 (2), 76-94. doi: http:// doi.org/10.1108/10650741311306273

[10] Ramanigopal, C. (2012). Knowledge Management Strategies in Higher Education. International Journal of Advanced Research in Management, 3 (1), 20-29. Available at: https://www.iaeme.com/MasterAd- 
min/UploadFolder/KNOWLEDGE \%20MANAGEMENT \%20STRATEGIES \%20IN \%20HIGHER \%20 EDUCATION.pdf

[11] Shams, R., Belyaeva, Z. (2017). Quality Assurance Driving Factors as Antecedents of Knowledge Management: a Stakeholder-focussed Perspective in Higher Education. Journal of Knowledge Economy, 1, 1-14. doi: http://doi.org/10.1007/s13132-017-0472-2

[12] Structural Reform of Education (2018). Ministry of Education and Science, the Republic of Lithuania. Available at: http://www.smm.lt/web/lt/smm-studijos/svietimo-strukturine-reforma

[13] Dayan, R., Heisig, P., Matos, F. (2017). Knowledge management as a factor for the formulation and implementation of organization strategy. Journal of Knowledge Management, 21 (2), 308-329. doi: http:// doi.org/10.1108/jkm-02-2016-0068

[14] Donate, M. J., Canales, J. I. (2012). A new approach to the concept of knowledge strategy. Journal of Knowledge Management, 16 (1), 22-44. doi: http://doi.org/10.1108/13673271211198927

[15] Fullwood, R., Rowley, J., Delbridge, R. (2013). Knowledge sharing amongst academics in UK universities. Journal of Knowledge Management, 17 (1), 123-136. doi: http://doi.org/10.1108/13673271311300831

[16] Gera, R. (2012). Bridging the gap in knowledge transfer between academia and practitioners. International Journal of Educational Management, 26 (3), 252-273. doi: http://doi.org/10.1108/09513541211213336

[17] Tubigi, M., Alshawi, S. (2015). The impact of knowledge management processes on organisational performance. Journal of Enterprise Information Management, 28 (2), 167-185. doi: http://doi.org/ 10.1108/jeim-01-2014-0003

[18] Abass, F., Hayat, M., Shahzad, A., Riaz, A. (2011). Analysis of Knowledge Management in the Public Sector of Pakistan. European Journal of Social Sciences, 19 (4), 471-478. Available at: https:// www.researchgate.net/publication/280296014_Analysis_of_Knowledge_Management_in_the_Public_ Sector_of_Pakistan

[19] Goh, S., Sandhu, M. (2013). Knowledge Sharing among Malaysian academics: Influence of Affective Commitment and trust. Electronic journal of Knowledge Management, 11 (1), 38-48. Available at: https://research.monash.edu/en/publications/knowledge-sharing-among-malaysian-academics-influenceof-affectiv

[20] Yusoff, M., Mahmood, A., Jaafar, J. (2012). A Study of Knowledge Management Enabler in a Malaysian Community College. Journal of Knowledge Management Practive, 13 (1). Available at: http:// www.tlainc.com/articl297.htm

[21] Chumjit, S. (2012). Knowledge Management in Higher Education in Thailand: Doctoral Thesis. Texas: The University of Texas at Arlington.

[22] Mavodza, J., Ngulube, P. (2012). Knowledge management practices at an institution of higher learning. SA Journal of Information Management, 14 (1). doi: http://doi.org/10.4102/sajim.v14i1.496

[23] Armey, L. E., Hosman, L. (2016). The centrality of electricity to ICT use in low-income countries. Telecommunications Policy, 40 (7), 617-627. doi: http://doi.org/10.1016/j.telpol.2015.08.005

[24] Lin, C., Wu, J.-C., Yen, D. C. (2012). Exploring barriers to knowledge flow at different knowledge management maturity stages. Information \& Management, 49 (1), 10-23. doi: http://doi.org/10.1016/ j.im.2011.11.001

[25] Shahdadi, H., Yazdanpenah, A., Ghavam, A. (2017). Investigate the Relationship between Information Technology and Employees‘ Productivity with Mediating Role of Knowledge Management. Middle East Journal of Family Medicine, 15 (6), 55-64. doi: http://doi.org/10.5742/mewfm.2017.92984

[26] Probst, G. (1998). Practical Knowledge Management: A Model that Works. Prism - Cambridge Massachusetts, 17-30. Available at: https://www.researchgate.net/publication/271508998_Practical_Knowledge_Management_-_A_Model_That_Works 